\title{
Dr Emmett Holt (1855-1924) and the foundation of North American paediatrics
}

\author{
Peter M Dunn
}

Luther Emmett Holt was born near Rochester, New York on 4 March 1855. Both his father Horace and his mother Sabrah came of New England puritan stock. After education at the Webster Academy and Rochester University, he entered the Medical College of Buffalo University in 1876. Transferring to the College of Physicians and Surgeons in New York the following year, he graduated in 1880 at the age of 25 . Within a year he resolved to devote himself to paediatrics, a specialty that was not then formally recognised. During the next few years he practised both from his own office and also from the North Western Dispensary, the New York Infant Asylum, Mount Vernon, and the New York Nursery and Children's Hospital. In 1889 he was offered the post of physician in charge of the Babies Hospital. Although the hospital was nearly defunct, he accepted the post, obtained financial backing and reorganised it. Over the years that followed, it became the most celebrated children's hospital in the USA. ${ }^{1}$

Holt was a small man. His voice was quiet and clear and his movements alert and quick. Always immaculately dressed, he rarely smiled or laughed and appeared to be driven by a stern sense of duty (fig 1). Hard working, efficient, thorough and meticulous in his work, he also possessed sound judgment, intellectual honesty, and a total dedication to the welfare of his patients. Children were treated as individuals. $\mathrm{He}$ remarked that "the best way to make friends with a child is not to try". He was not interested in speculation, nor was he possessed of an imaginative mind. His approach was always intensely practical and concerned with knowledge that might help to solve problems. Besides being a great clinician, he was also a born teacher. His interests extended beyond the illnesses of children to a wish to ensure that they grew up healthy-physically, mentally, and morally. In this he was decades ahead of most of his contemporaries throughout the world. Holt developed fixed routines in management which were applied with vigour. $\mathrm{He}$ expected the highest standards from his assistants but never gave praise or formed close friendships. Nor was he ever unkind.

During his career, Holt published three books and 170 papers on a wide variety of subjects. His first book on the care and feeding of

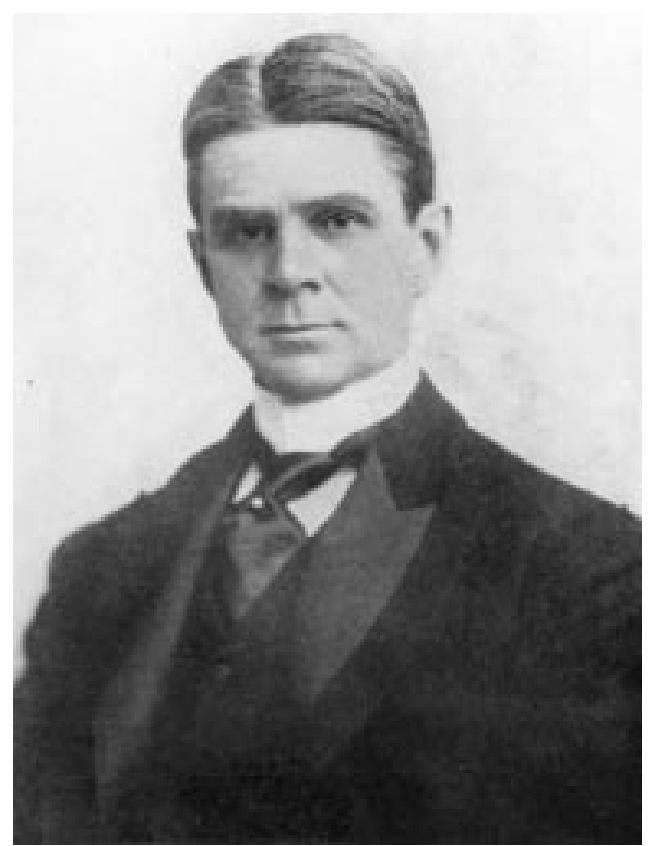

Figure 1 Luther Emmett Holt (1855-1924).

children, published in 1894 and passing through 75 editions or printings, was designed for the training of nursemaids. It was translated into many languages. His second, published in 1897, had the title The diseases of infants and children. ${ }^{2}$ Written in simple clear language, it gave an orderly presentation of paediatric knowledge at that time. Lifting child sickness and care out of the neglect of the past, it became the standard paediatrics text in America. The following extracts from it give an idea of his approach to newborn care.

\section{On the prevention of children's diseases ${ }^{2}$}

"There is no more promising field in medicine than the prevention of disease in childhood. The majority of ailments from which children die, it is within the power of man in great measure to prevent. Prophylaxis should aim at the solution of two distinct problems: (1) the removal of the causes which interfere with the proper growth and development of children; (2) the prevention of infection. The former can only come through the education first of the profession and then the general public, in the funda- 
mental principles of infant feeding and hygiene. This is a department that has received altogether too small a place in medical education. The latter must come through the profession, and through legislation, the purpose of which shall be more rigid quarantine, more thorough disinfection, and improved sanitation in all its departments."

\section{On the management of birth asphyxia}

"In the livid cases relief is often afforded by allowing the cord to bleed for a few minutes before ligation. The loss of half an ounce of blood is ordinarily sufficient."

"(When) there is no response whatever to external stimulation, either by heat or mechanical irritation ...two methods of resuscitation may be employed: artificial respiration and direct inflation of the lungs ... .it is sometimes successful when all other means have failed. It may be done by mouth-tomouth method, or by the introduction of a catheter into the larynx. The former is much easier, but is much less certain, since the air is liable to pass into the stomach ... The introduction of a flexible catheter into the larynx is by no means an easy matter even with considerable practice. The use of a stiff catheter is not so difficult, but it is capable of doing harm. A much better instrument is the laryngeal tube of Ribemont (fig 2). This is inserted like an intubation tube. By means of the rubber bag attached, air may be forced into the lung, or mucus aspirated from the trachea and bronchi as may be desired. In all these methods, but especially when the catheter is used, care is necessary not to employ too much force. It should always be remembered that the capacity of the lungs of a child is much less than that of the physician."

\section{On pasteurising milk $^{2}$}

"The temperature of $167^{\circ} \mathrm{F}$, maintained for twenty minutes, has been shown sufficient to destroy the bacilli of cholera, typhoid fever, diphtheria, tuberculosis, bacterium coli commune and the ordinary pyogenic germs. It does not, however, destroy spores, and milk thus treated will keep at ordinary room temperatures for two or three days only, but on ice for several days. Milk heated to $167^{\circ} \mathrm{F}$ has no objectionable taste, and . . the character of the curd and its digestibility do not differ from that of ordinary milk ... To my knowl-


Figure 2 The laryngeal tube of Ribemont. edge, no sufficient evidence has yet been adduced to establish the fact that milk so heated has lost any of its essential nutritive properties, or that children fed exclusively upon it exhibit signs of either of the two most marked disorders of nutrition - rickets or scurvy ... It should be distinctly understood that sterilised milk requires the same modifications for infant feeding as plain milk."

\section{On neonatal tetanus ${ }^{2}$}

"The discovery of the exact cause of tetanus is due to the work of Nicolaier, who in 1884 found a bacillus in the soil, with which he produced the disease in animals. He demonstrated the presence of this bacillus in the wounds of tetanus patients. Nicolaier did not, however, obtain the germ in pure culture: but this was done by Kitasato in $1889 \ldots$ The rapidity with which the infection spreads from the point of inoculation is very remarkable ... The bacilli are not found in the blood or internal organs. The symptoms of the disease have been shown to depend upon the absorption of a toxic product of the tetanus bacillus called tetanotoxine. The germ of tetanus usually gains access to the body of the infant through the umbilical wound.

A proper understanding of the nature of the disease has brought with it the means of rational prevention. The first essential is obstetrical cleanliness, which must include scissors, hands, dressings, ligatures - in short, everything which comes into contact with the umbilical wound . . . Behring and Kitasato ... have produced a substance called tetanus antitoxine which has the power of neutralising the tetanus poison ... The treatment is not efficient unless it is adopted very early in the disease . . .it is used subcutaneously like the diphtheria antitoxine."

\section{On tongue-tie ${ }^{2}$}

"This deformity is due to such a shortening of the frenum that it is impossible to protrude the tongue to a normal extent. It differs considerably in degree in different cases. In some, the tongue cannot be advanced beyond the gums. Tongue-tie may interfere with articulation, and even with sucking. The treatment consists in liberating the tongue by dividing the frenum with scissors and completing the operation with the finger nail. This should be done in every case unless the child is a bleeder. In many cases the mother may think the tongue-tied when the frenum is of normal length."

\section{On haemorrhagic disease of the newly} born ${ }^{2}$

“. . the haemorrhages are not associated with any other known process ... they are spontaneous in origin, having no connection with delivery, they are multiple in location, and, while little influenced by treatment, they tend to cease spontaneously after quite a limited time. They are most often from the 
umbilicus, the mucus membranes of the stomach and intestines, or beneath the skin . . Exactly what causes these haemorrhages is as yet unknown . . . These cases . . .are not manifestations of haemophilia ... The tendency to bleed . . .often lasts but a few days; those who survive, recover perfectly ... The time of beginning is most frequently in the first week of life, rarely after the 12 th day ... the disease .. .has a bad prognosis ... The administration of drugs internally for the control of haemorrhage is, in my opinion, entirely without influence upon the disease ..."

Forty two years later in 1939, Holt's son, editing the 11 th edition of his text with Rustin Mackintosh, was in a position to throw more light on this subject.

On haemorrhagic disease of the newborn ${ }^{3}$

"Prothrombin is formed in the liver through the agency of vitamin K... Green vegetables furnish the normal supply of vitamin $\mathrm{K}$... Many bacteria can synthesize quinones with vitamin $\mathrm{K}$ activity (including) normal intestinal flora, such as the colon bacillus ... the natural forms of vitamin $\mathrm{K}$ are fat soluble ... A tendency to bleed spontaneously may appear within the first three or four days after birth ... The prothrombin content of the blood at birth is roughly one-fourth of the adult value ... The low prothrombin of the infant seems to be due to failure to receive sufficient vitamin $\mathrm{K}$ in utero. The administration of the vitamin to the mother, even as late as an hour or two before delivery, increases the infant's prothrombin sufficiently to protect him from haemorrhage ... Haemorrhagic disease may now be regarded as a preventable disorder. The effectiveness of vitamin K given before delivery . . . is now well established. Not only can spontaneous haemorrhage be practically eliminated by this procedure, but statistics from several clinics indicate a striking reduction in haemorrhages formerly regarded as traumatic. Prothrombin deficiency can, as a rule, be readily controlled by oral administration of vitamin $\mathrm{K}$... We have found thyloquinone (2 methyl, 1-4 naphthoquinone) eminently satisfactory ... For infants an initial dose of $0.5 \mathrm{mg}$ may be given . . . oral administration usually causes cessation of bleeding within two or three hours."

Many honours came Holt's way. He was a founder member of the American Pediatric Society in 1888 and twice its President (1897 and 1923). He also helped in 1884 to found the first American paediatric journal, the Archives of Pediatrics, and was for many years its editor. He was a long time member of the Board of the Rockefeller Institute, and in 1901 succeeded Abraham Jacobi as Professor of Pediatrics at the College of Physicians and Surgeons. He was Treasurer and Vice President of the New York Academy of Medicine and President of the Child Health Organisation (1919) which became the American Child Health Association in 1923. In 1902 Rochester University awarded him the degree of LLD, while both Columbia University (1904) and Brown University (1914) made him a DSc. In 1908 he attended the Congress of Medicine in Europe where he was recognised as the leader of American pediatrics.

Emmett married and the family had a farm in Pleasantville near New York and used to spend their holidays there or at a summer camp in the Adirondacks. To his son, Elliot Holt Jr, he wrote: "I hope you will not lose interest in the clinical side of pediatrics, for it is only its practical application which justifies research, according to my way of thinking".

Holt had a sense of mission to improve child care, and the foundation of paediatrics and child health in the USA was his lasting achievement. On 4 January 1924, he died of a coronary heart attack while visiting the Peking Union Medical College in China.

1 Park EA, Mason HH. Luther Emmett Holt. In: Pediatric profiles. St Louis: CV Mosby Co, 1957.

2 Holt LE. The diseases of infancy and childhood. New York: D Appleton and Co, 1897.

3 Holt LE, Howland J. Holt's diseases of infancy and childhood [revised by L E Holt, Jr, R McIntosh]. 11th ed. New York: D Appleton-Century Co, 1939. 